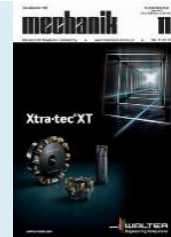

Authors: Paweł Majda, Joanna Jastrzębska

Title of article: „Praktyczne aspekty doboru modelu numerycznej kompensacji błędów geometrycznych obrabiarek” (“Selection of numerical compensation model of geometric errors of machine tools")

Mechanik, Vol. 91, No. 11 (2018): pages 980-983

DOI: https://doi.org/10.17814/mechanik.2018.11.175

\title{
Selection of numerical compensation model of geometric errors of machine tools
}

\author{
Praktyczne aspekty doboru modelu numerycznej kompensacji \\ błędów geometrycznych obrabiarek
}

\author{
PAWEK MAJDA \\ JOANNA JASTRZĘBSKA *
}

angular and mutual squareness of translational numerically controlled axes. In this approach, the machine tool with the indexed position of the tool head is also classified as threeaxis. Analytical considerations were carried out for the entire population of geometrical and motion structures of threeaxis machine tools with a serial kinematic structure.

Manufacturers of CNC control systems for machine tools - e.g. Fanuc, Heidenhain, Siemens et al. - they propose various machine error compensation options according to ISO TR 16907 [4]. The purpose of the article is to provide information on the selection of the appropriate method and / or VE error model for a three-axis machine tool, taking into account its functional features. Achievement of the goal formulated in this way will allow: rational support of the selection of measuring means, determination of the scope of measurements necessary for the measurements, and purchase of the machine compensation option from the control manufacturer.

Selection of the reference system for the numerical model of geometric error compensation of three-axis machine tools

The VE model itself is built with the assumption of motion kinematics perfectly rigid. The modeling of the motion of the machine carrier system blocks (UNO) with regard to geometric errors is most often carried out using homogeneous matrix transformations [5-7]. At the outset, it is crucial to specify a reference system in which the VE error distribution will be modeled. According to the standard [3], the coordinate system of the machine tool is the right-hand rectangular system. Classically, individual UNO elements are assigned designations of the axis of the reference system in directions in which they move rectilinearly $(X, Y$, $Z$ ) or rotational (around the next axes $A, B, C$ ). The position and orientation of the machine coordinate system is defined using the reference line of the guide movement axis of the guide connections. It is based on selecting the main axis of motion, so that the reference line is aligned with one axis of the machine coordinate system - in this way two orientation parameters and an orthogonal plane are determined. Next, the secondary axis is selected - in such a way that its reference line is parallel to the next axis of motion - and the third orientation parameter is defined, resulting from the projection of the reference line on the previously defined plane. At the end, the origin of the machine coordinate system is selected, defining three position parameters. The selection of the main axis, secondary axis and the origin of the machine coordinate system depends on its construction

\footnotetext{
* Dr hab. inż. Paweł Majda (pawel.majda@zut.edu.pl), mgr inż. Joanna Jastrzebska (joanna.jastrzebska@zut.edu.pl) - Wydział Inżynierii Mechanicznej i Mechatroniki Zachodniopomorski Uniwersytet Technologiczny w Szczecinie
} 
and the possibility of mechanical correction and mechanical and / or program (numerical) compensation of errors. As standard [1,2], the direction and position of the Z-axis of machine tools (milling machines and lathes) coincides with the direction and position of the $C$ axis, i.e. the main drive (spindle). It should be noted that in a triaxial machine there is no possibility of numerically compensating for the parallel parallelism of reference lines of the $C$ and $Z$ axes, and therefore the squareness of the tool axis with respect to the $X$ and $Y$ axes. The occurrence of this error is very undesirable in the context of drilling deep holes. Moving the tool in the $Z$ axis will be accompanied by breaking the diameter of the hole. In this approach, the $Z$ axis should be treated as the main axis of the machine coordinate system, because it is the assembly axis that is the basis of the spindle $C$ axis to minimize machine errors, which can not be compensated numerically. For the same reason, the orientation of the system in which the VE model will be built should also be based on the $Z$ axis. Fulfilling this criterion will be equivalent to the elimination of numerical error compensation for squareness of $X$ and $Z$ axes and/or $Y$ and
$Z$ axes during $Z$ axis motion These errors will be compensated during the movement of $X$ or $Y$ axes and will not affect the accuracy of the formation of deep holes.

Further considerations require the adoption of the error marking convention. Exemplary designations in accordance with the ISO $230-x$ series of standards are shown in fig. 1.

It should be noted that the case presented in fig. 1b will ensure the correct selection of the reference system for modeling the VE error of a three-axis machine tool in hole machining. The variant shown in fig. 1a can be used to compensate for machine tool errors assuming that the tool will never be used to drill holes (e.g. in specialized machining). However, for typical machine tools, this would not have practical reasons. As a consequence of adopting the basic axis in relation to which the orientation of the remaining axes is determined in the VE model, it is appropriate to record squareness errors in the matrices of homogeneous transformations of the VE model. These matrices for the cases shown in fig. 1 are given in the tab. I.

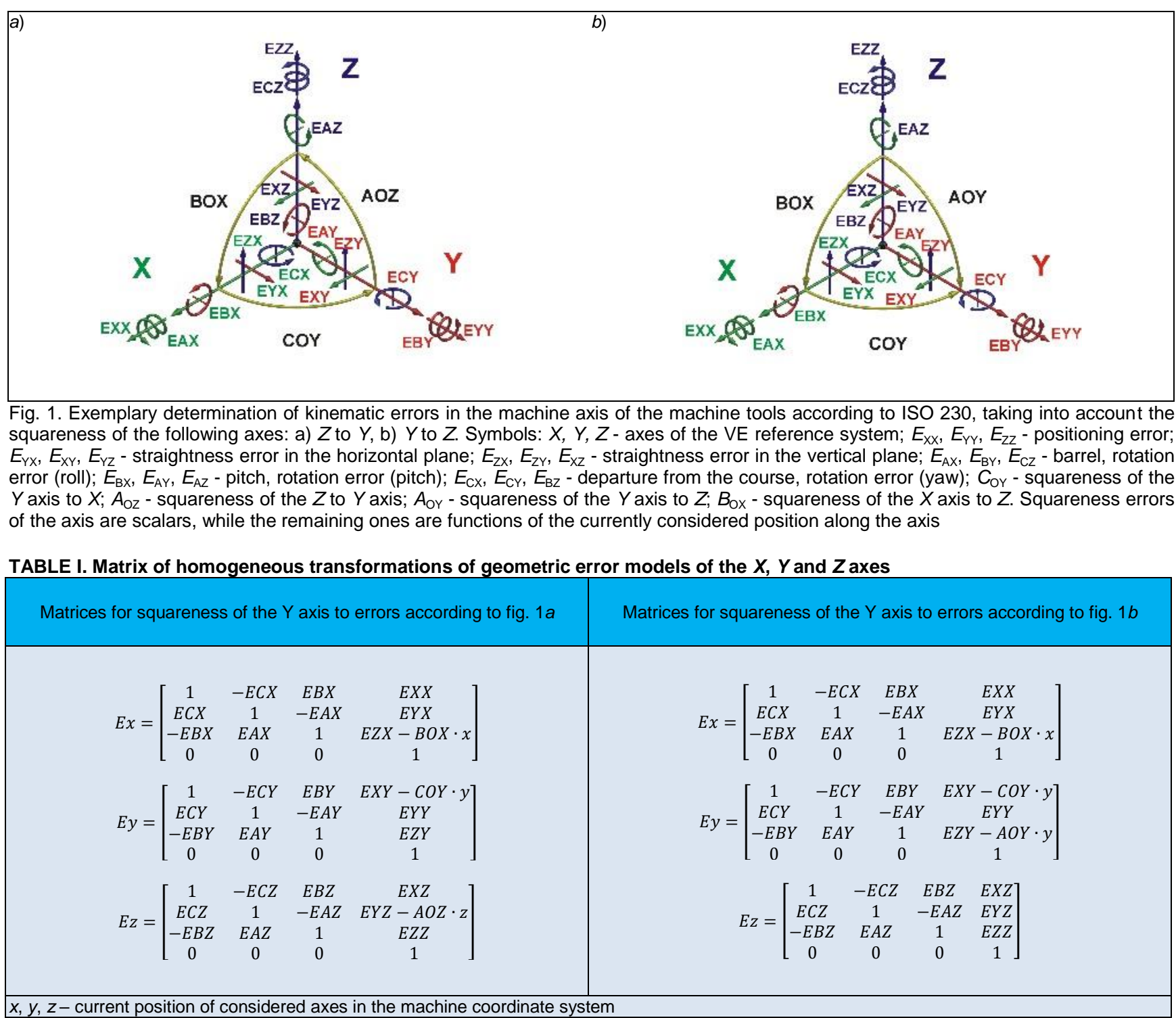

\section{Geometric and motor structures of serial kinematics machines}

The kinematics of the working process of machine tools is the result of mutual movements of the UNO body elements. These movements are routed through guide connections. The arrangement of these connections - called the guide system - is the implementation of the so-called geometrical-motor structures (SG-R). This is reflected in the structure written by Wragow [9], according to which in the so-called a structured formula is placed unambiguous information about the possibility of implementing movements of UNO elements. When the classic convention of $X, Y, Z$ axis designations and subsequent rotary axes $A$, 
$B, C$ is used, and the fixed stationary body (stand, bed, base) is marked with the $O$ symbol, then the structural formula is constructed as: [workpiece - $w$ (workpiece)] $\rightarrow$ symbols of the coordinate system axes corresponding to the directions of displacements of consecutive UNO elements together with the designation of the stationary body $\rightarrow$ [tool $t$ (tool)]. By adjusting (permutations without repetition) the axis designations $(X, Y, Z)$ with the stationary body $(O)$ for a three-axis machine tool, a total of 24 (4!) Structural patterns SG-R, i.e. 24 variants of the body system (fig. 2) are obtained. In Poland, the SG-R research was carried out by G. Szwengier's team due to various machine design criteria.

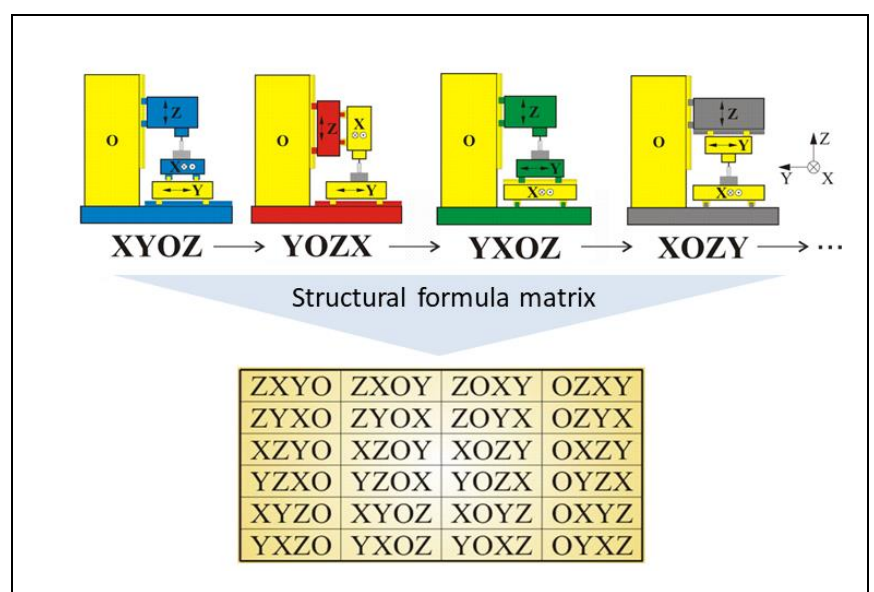

Fig. 2. SG-R patterns of a three-axis machine tool

For one SG-R three-axis machine tool, due to the modeling of the VE distribution, account should be taken of the tool overhang, understood in accordance with the concepts used in machining technology. The overhang can be defined, for example, relative to the point of the tool holder, although in general it does not have to be this way. Possible cases are shown in fig. 3 - variant with indexed tilting and rotary head is treated as a general case of a three-axis machine tool. It is further shown that the VE model is subject to appropriate simplifications depending on the variant of the tool overhang.

\section{Simplification of the spatial positioning model of machines}

After performing mathematical operations in the convention of modeling the motion of a rigid body using homogeneous matrix transformations, the formulas for the VE error are projected, projected onto the $X, Y$ and $Z$ axes respectively. The calculations omit - as irrelevant components of errors in the second and higher power. For example, for SG-R with an indexed position of the spindle position, i.e. for the structure WOXYZCA(C)t, i.e. for the FRB model (see fig. 3), in the reference system according to fig. $1 \mathrm{~b}$, the formulas look as follows:

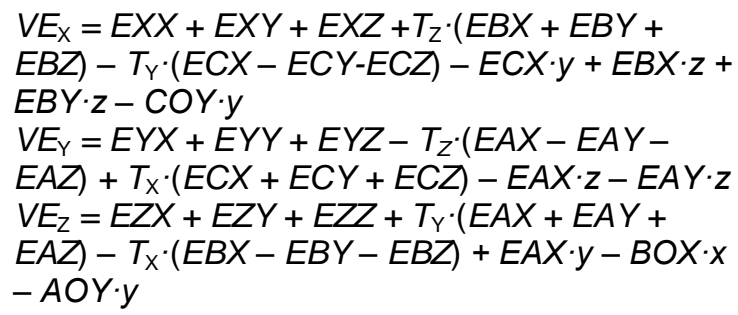

For the RRB-I model, i.e. for $T_{X}=0$ and $T_{Y}=0$, the formulas simplify to the form:

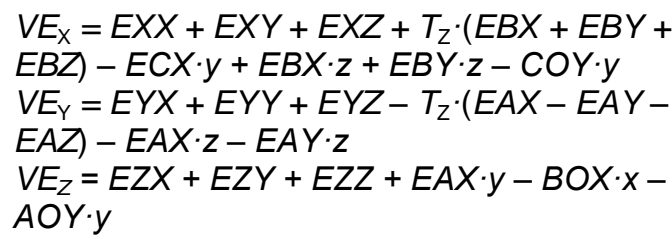

In turn, for the RRB-II model, that is for $T_{X}=0, T_{Y}=0$ and $T_{Z}=0$, the formulas have the form:

$$
\begin{aligned}
& V E_{X}=E X X+E X Y+E X Z-E C X \cdot y+E B X \cdot z+ \\
& E B Y \cdot z-C O Y \cdot y \\
& V E_{Y}=E Y X+E Y Y+E Y Z-E A X \cdot z-E A Y \cdot z \\
& V E_{Z}=E Z X+E Z Y+E Z Z+E A X \cdot y-B O X \cdot x- \\
& A O Y \cdot y
\end{aligned}
$$
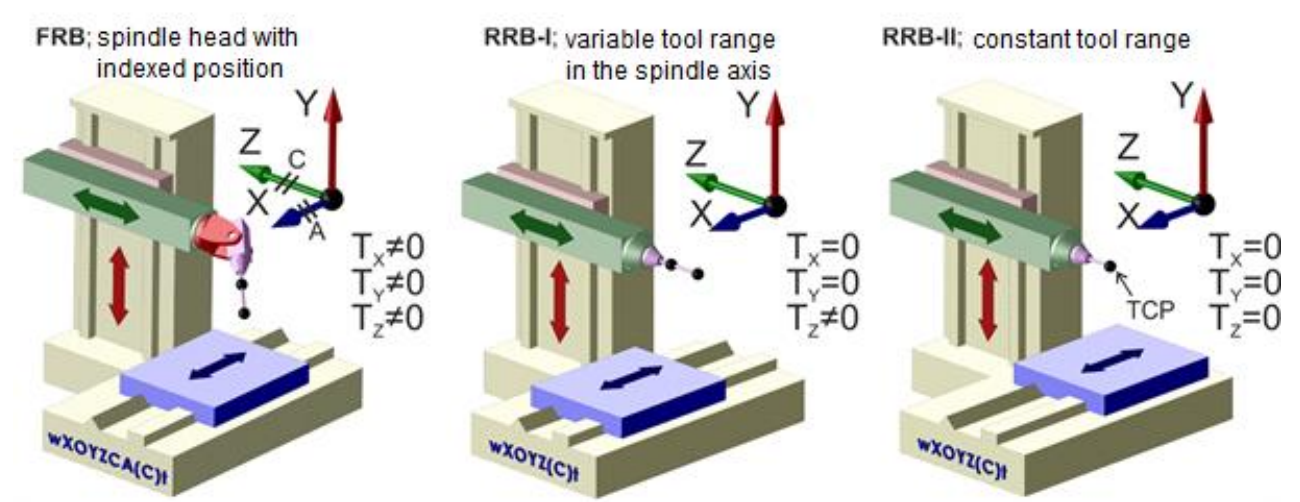

Fig. 3. Kinds of the tool's reach and corresponding names of simplified models of motion of the rigid body of a three-axis machine tool: FRB (full rigid body), RRB (reduced rigid body). Marks: $T_{X}, T_{Y} T_{Z}$ - tool overhang in the direction of the $X, Y$ and $Z$ axes

As it can be seen, depending on the considered variant of the tool overhang, simplifications are made in the formulas to eliminate the appropriate angular errors.

The positioning errors, straightness and mutual squareness of the axes occur in each model, i.e. FRB, RRBI and RRB-II for each SG-R. In the FRB model, for all SG-R, all geometrical errors are considered. In the RRB-II model of the WOXYZ $_{\mathrm{O}}$ structure (see fig. 3), four angular errors were eliminated: $E_{\mathrm{CY}}, E_{\mathrm{AZ}}, E_{\mathrm{BZ}}$ and $E_{\mathrm{CZ}}$. This means that the movement of the central point of the $T_{\mathrm{CP}}$ tool is independent of these errors. There is no need to determine them in measurements and to include them in the CNC control system as a compensating correction of the $T_{\mathrm{CP}}$ position.

Due to the implementation of analogous calculations for the other SG-R, results were obtained based on which a juxtaposition of angular errors for the RRB-II model was created (tab. II). 
TABLE II. RRB-II model angular error table for different SG-Rs

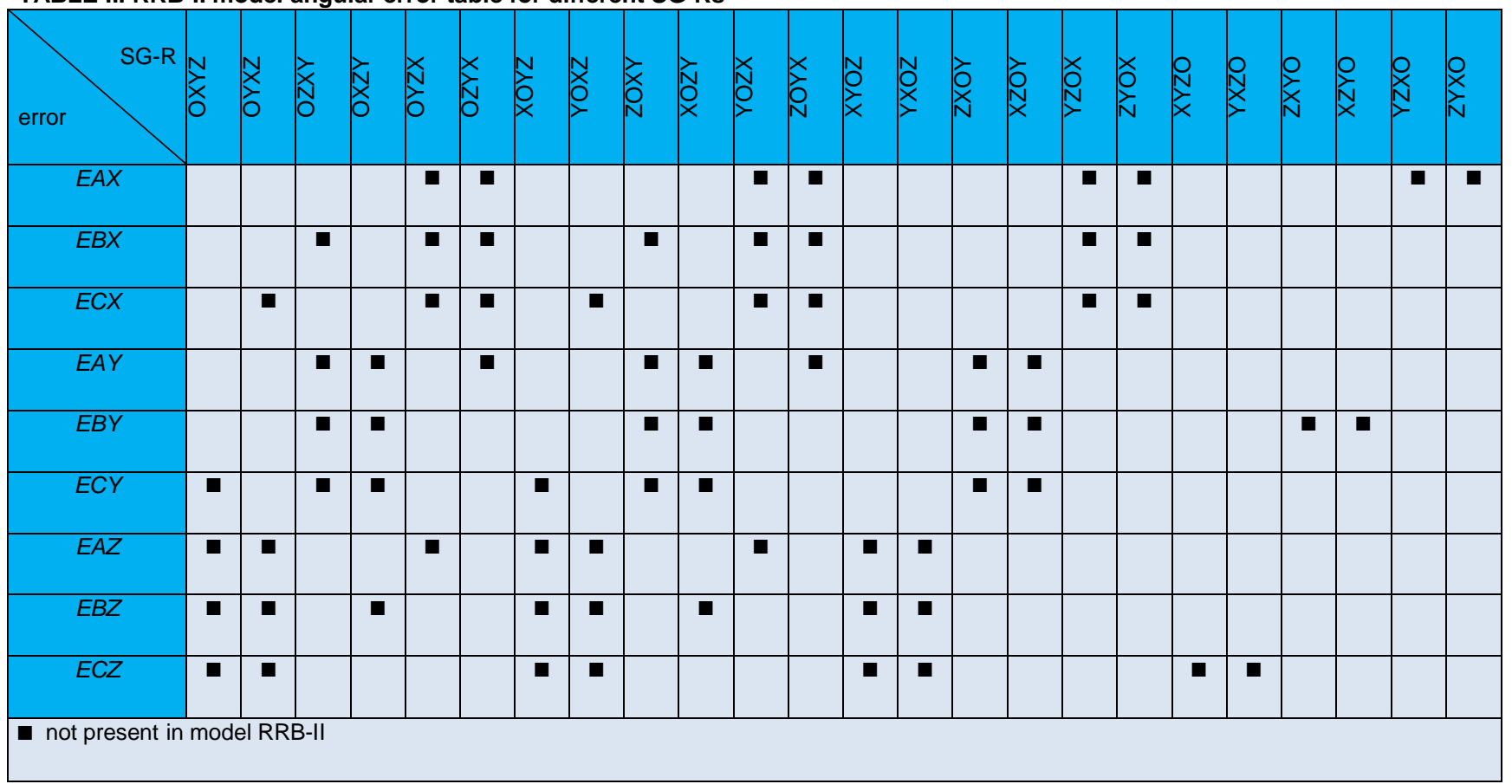

\section{Conclusions}

The analytical results of the spatial positioning model (VE model) model for three-axis machine tools presented in the article allow to formulate a general conclusion: the type of geometry and motion structure of the carrier system determines the form of spatial positioning error patterns (i.e. VE error) due to the impact of tool and error angular (pitch, yaw, roll). The influence of the impact factors considered here should always be taken into account when planning the scope of geometric error measurements of the machine tool and when selecting the option of compensating them in the CNC controller. Thanks to this you can save time and money.

From the whole SG-R population (see the matrix of the formulas in fig. 2) of the three-axis machine tools, the most resistant to the tool overhang, multiplied by angular errors, are the structures for which the determination of the " $O$ " stationary body in the structural formula occurs at the beginning. In these cases, the largest number of angular errors is reduced (see SG-R in tab. II). This is probably the main reason why coordinate measuring machines are designed as portal and - possibly - with a movable (in one axis) table relative to the stationary body.

In addition, the key to selecting a reference system for the spatial positioning error model is to consider the machining tasks that the machine tool is to perform. This decides about the direction of compensation for errors in the squareness of the numerically controlled axes during the implementation of straight-line movements. The omission of this criterion will lead in specific situations (e.g. when drilling deep holes) to the deterioration of the accuracy of shaping workpieces when using numerical compensation of machine tool errors.

\section{REFERENCES}

1. ISO 10791-1:2015 Test conditions for machining centres Part 1. Geometric tests for machines with horizontal spindle (horizontal $Z$-axis).

2. ISO 10791-2:2001 Test conditions for machining centres Part 2. Geometric tests for machines with vertical spindle or universal heads with vertical primary rotary axis (vertical $Z$ axis).

3. ISO 841:2001 Industrial automation systems and intergration. Numerical control of machines. Coordinate system and motion nomenclature.

4. ISO TR-16907:2015 Machine tools - numerical compensation of geometric errors.

5. Okafor A.C., Ertekin Y.M. "Derivation of machine tool error models and error compensation procedure for three axes vertical machining center using rigid body kinematics". International Journal of Machine Tools \& Manufacture. 40 (2000): pp. 1199-1213.

6. Schwenke H., Knapp W., Haitjema H., Weckenmann A., Schmitt R., Delbressine F. "Geometric error measurement and compensation of machines - an update". CIRP Annals - Manufacturing Technology. 57, 2 (2008): pp. 660-675.

7. Smith G.T. "Machine Tool Metrology. An Industrial Handbook". Springer, ISBN 978-3-319-25109-7, 2016.

8. Szwengier G. „Modelowanie i obliczenia projektowe układów prowadnicowych obrabiarek". Prace naukowe Politechniki Szczecińskiej nr 512. Szczecin: Wydawnictwo Uczelniane Politechniki Szczecińskiej, 1994.

9. Vragov J.D. „Analiz komponovok metallorežuščich stankov. Osnovy komponetiki". Moskva: Mašinostroenie, 1978. .

Translation of scientific articles, their computer composition and publishing them on the website www.mechanik.media.pl by original articles in Polish is a task financed from the funds of the Ministry of Science and Higher Education designated for dissemination of science. 